\title{
Stimuli-Responsive Self-Assembly of $\pi$-conjugated Liquids Triggers Circularly Polarized Luminescence
}

Ayumi Ikenaga, ${ }^{\dagger}$ Yuichi Akiyama, ${ }^{\dagger}$ Tatsuya Ishiyama, ${ }^{* \|}$ Masayuki Gon,${ }^{\S}$ Kazuo Tanaka, ${ }^{\S}$ Yoshiki Chujo, Kyosuke Isoda, ${ }^{* \# \sharp}$

${ }^{\dagger}$ Division of Advanced Materials Science, Graduate School of Engineering, Kagawa University, 2217-20 Hayashi-cho, Takamatsu, Kagawa 761-0396, Japan

\#Program in Advanced Materials Science, Faculty of Engineering and Design, Kagawa University, 2217-20 Hayashicho, Takamatsu, Kagawa 761-0396, Japan

"Department of Applied Chemistry, Graduate School of Science and Engineering, University of Toyama, 3190 Gofuku, Toyama 930-8555, Japan

$\S$ Department of Polymer Chemistry, Graduate School of Engineering, Kyoto University, Katsura, Nishikyo-ku, Kyoto 615-8510, Japan

*Health and Medical Research Institute, National Institute of Advanced Industrial Science and Technology (AIST), 2217-14 Hayashi-cho, Takamatsu, Kagawa 761-0395, Japan

Email: isoda.kyosuke@kagawa-u.ac.jp; ishiyama@eng.u-toyama.ac.jp 
S1. Synthesis<smiles>CC(C)CCCC(C)CCC(C)CCC(C)CCCC(C)CCCC(C)CCOc1ccccc1O</smiles><smiles>CC(C)CCCC(C)CCCC(C)CCOc1cc([N+](=O)[O-])c([N+](=O)[O-])cc1OCCC(C)CCC(C)CCCC(C)CCCC(C)CCCC(C)CCCC(C)CCC(C)C</smiles>

$3 R$

$2 R$

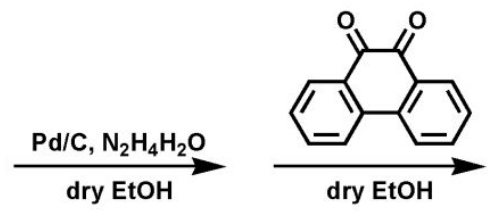<smiles>[R]C(CCCC(C)C)CCOc1cc2nc3c4ccccc4c4ccccc4c3nc2cc1OCCC(C)CCCC(C)CCCC(C)C</smiles><smiles>CC(C)CCCC(C)CCCC(C)CCOc1ccccc1O</smiles><smiles>CC(C)CCCCCCC(C)C(C)(C)C(=O)O</smiles><smiles>CC(C)CCCC(C)CCCC(C)CCCC(C)CCCC(C)CCC([13CH3])CCOc1cc([N+](=O)[O-])c([N+](=O)[O-])cc1OCCC(C)CCCC(C)CCCC(C)C</smiles>

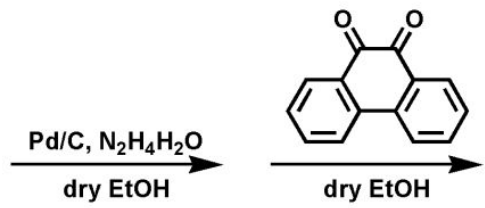<smiles>CC(C)CCCOc1cc2nc3c4ccccc4c4ccccc4c3nc2cc1OCCC(C)CCCC(C)CCCC(C)C</smiles>

15

Scheme S1. Syntheses of c-SRL $1 R$ and $\mathbf{1 S}$. 


\section{2-(3,7-Dimethyloctacyloxy)-phenol (5)}

A suspension of 3,7,11-trimethyl-1-dodecanol (5.83 g, $20 \mathrm{mmol})$, catechol (2.75 g, $25 \mathrm{mmol})$, and $\mathrm{Cs}_{2} \mathrm{CO}_{3}$ $(8.14 \mathrm{~g}, 25 \mathrm{mmol})$ in DMF $(100 \mathrm{~mL})$ was heated at $80^{\circ} \mathrm{C}$ under an Ar atmosphere for $24 \mathrm{~h}$. After this time, the reaction mixture was poured into water, extracted three times with EtOAc, and dried over anhydrous $\mathrm{Na}_{2} \mathrm{SO}_{4}$. After filtration and evaporation, the crude product was purified by column chromatography (silica, hexane/ $\left.\mathrm{CHCl}_{3}=2 / 1\right)$, and dried under vacuum to afford 5 as a transparent liquid (2.94 g, 45.8\%). ${ }^{1} \mathrm{H}$ NMR (400 MHz, $\left.\mathrm{CDCl}_{3}\right)$ : $\delta$ 6.94-6.82 (m, 4H), 4.11-4.06 (m, 2H), 1.89-1.85 (m, 1H), 1.68-1.85 (m, 2H), 1.39$1.08 \quad(\mathrm{~m}, \quad 14 \mathrm{H}), \quad 0.98-0.82 \quad(\mathrm{~m}, \quad 14 \mathrm{H}) \quad \mathrm{ppm} ; \quad{ }^{13} \mathrm{C} \quad \mathrm{NMR} \quad\left(75 \quad \mathrm{MHz}, \quad \mathrm{CDCl}_{3}\right)$ : $\delta 145.97,145.83,121.29,120.04,114.42,111.59,67.24,39.36,37.38,37.36,37.34,37.31,37.26,36.28$, $36.19,32.78,29.93,27.97,24.80,24.79,24.36,22.71,22.61,19.73,19.65 \mathrm{ppm}$; IR (ATR): $v=3550,2925$, $2869,1602,1597,1501,1466,1366,1301,1258,1223,1197,1105,1035,1014,979,911,737,437 \mathrm{~cm}^{-1}$; MS(MALDI-TOF): m/z calcd: 320.51 [M] $]^{+}$; found: 320.37; elemental analysis: calcd (\%) for $\mathrm{CH}: \mathrm{C} 78.69$, H 11.32; found: C 78.86, H 11.65 .

\section{1-(3,7-Dimethyldodecyloxy)-2-(3R)-(3,7-dimethyloctcyloxy)benzene ( $3 R$ )}

Compound $\mathbf{3} \boldsymbol{R}$ was prepared according to the procedure used to obtain $\mathbf{5}$. More specifically, $\mathbf{5}(1.60 \mathrm{~g}, 5$ $\mathrm{mmol})$ instead of catechol, $4 \boldsymbol{R}(1.12 \mathrm{~g}, 5 \mathrm{mmol}), \mathrm{Cs}_{2} \mathrm{CO}_{3}(1.63 \mathrm{~g}, 5 \mathrm{mmol})$, and DMF ( $\left.80 \mathrm{~mL}\right)$ were used. The crude product was purified by column chromatography (silica, hexane $/ \mathrm{CHCl}_{3}=4 / 1$ ), and dried under vacuum to afford $\mathbf{3 R}$ as a transparent liquid $(1.20 \mathrm{~g}, 78.4 \%) .{ }^{1} \mathrm{H}$ NMR $\left(400 \mathrm{MHz}, \mathrm{CDCl}_{3}\right): \delta 6.91-6.90(\mathrm{~m}$, 4H), 4.06-4.02 (m, 4H), 1.90-1.88 (m, 2H), 1.70-1.51 (m, 5H), 1.32-1.10 (m, 19H), 0.97-0.88 (m, 22H) ppm; ${ }^{13} \mathrm{C}$ NMR $\left(75 \mathrm{MHz}, \mathrm{CDCl}_{3}\right): \delta 149.34,121.01,114.21,67.70,39.39,39.30,37.52,37.49,37.43,37.40$, $37.31,36.37,36.35,32.82,29.98,29.96,27.98,24.82,24.80,24.71,24.41,22.71,22.69,22.60,19.75$, 19.71, 19.69, 19.66 ppm; IR (ATR): $\mathrm{n}=2932,2924,2867,1593,1503,1463,1454,1383,1366,1331$, 1252, 1221, 1122, 1048, 1038, 982, $736 \mathrm{~cm}^{-1}$; MS(MALDI-TOF): $\mathrm{m} / \mathrm{z}$ calcd: 460.78 [M] ${ }^{+}$; found: 483.57; elemental analysis: calcd (\%) for CH: C 80.81, H 12.25; found: C 80.71, H 12.49.

\section{4-(3,7-Dimethyldodecyloxy)-5-(3R)-(3,7-dimethyloctcyloxy)-1,2-dinitrobenzene (2R)}

A solution of $3 \boldsymbol{R}(1.84 \mathrm{~g}, 4.0 \mathrm{mmol})$ in $\mathrm{CH}_{2} \mathrm{Cl}_{2}(50 \mathrm{~mL})$ and $\mathrm{CH}_{3} \mathrm{COOH}(20 \mathrm{~mL})$ was stirred at $0{ }^{\circ} \mathrm{C}$ for $10 \mathrm{~min}$. Subsequently, $\mathrm{HNO}_{3}(5.0 \mathrm{~mL})$ was added dropwise to the solution and stirred. After $20 \mathrm{~min}$, fuming $\mathrm{HNO}_{3}(10 \mathrm{~mL})$ was dropwise to the solution and stirred at r.t. for $48 \mathrm{~h}$. The reaction mixture was then poured into water, extracted with $\mathrm{CHCl}_{3}$, washed three times with $\mathrm{H}_{2} \mathrm{O}$, and dried over anhydrous $\mathrm{NaHCO}_{3}$. After filtration and evaporation, $2 \boldsymbol{R}$ was obtained as a yellow solid $(1.61 \mathrm{~g}, 74.8 \%){ }^{1} \mathrm{H}$ NMR (400 MHz, $\left.\mathrm{CDCl}_{3}\right): \delta 7.31(\mathrm{~m}, 2 \mathrm{H}), 4.12(\mathrm{~m}, 4 \mathrm{H}), 1.91(\mathrm{~m}, 2 \mathrm{H}), 1.68-1.03(\mathrm{~m}, 29 \mathrm{H}), 0.98(\mathrm{~m}, 6 \mathrm{H}), 0.88(\mathrm{~m}, 16 \mathrm{H}) \mathrm{ppm}$; ${ }^{13} \mathrm{C}$ NMR $\left(75 \mathrm{MHz}, \mathrm{CDCl}_{3}\right): \delta 151.81,136.50,107.87,68.67,39.37,39.18,37.38,37.33, \quad 37.31,37.29$, $37.19,37.16,35.67,35.61,32.81,29.91,29.90,27.97,24.81,24.68,24.38,22.70,22.68,22.61,22.58$, 19.72, 19.65, 19.62, 19.59 ppm; IR (ATR): $\mathrm{n}=2930,2924,2869,1587,1527,1464,1373,1334,1290$, 
1220, 1035, 958, 874, 869, 811, 751, 719, 664, $619 \mathrm{~cm}^{-1}$; MS(MALDI-TOF): m/z calcd: 550.77 [M] found: 573.57; elemental analysis: calcd (\%) for CHN: C 67.60, H 9.88, N 5.09; found: C 67.64, H 10.01, N 4.96.

1-(3,7-Dimethyldodecyloxy)-2-(3S)-(3,7-dimethyloctcyloxy)benzene (3S)

Compound $3 S$ was prepared according to the procedure used to obtain $3 R$. More specifically, $4 \boldsymbol{S}$ ( $2.21 \mathrm{~g}$, $10 \mathrm{mmol}), \mathbf{5}(3.20 \mathrm{~g}, 10 \mathrm{mmol}), \mathrm{Cs}_{2} \mathrm{CO}_{3}(3.25 \mathrm{~g}, 10 \mathrm{mmol})$, and DMF $(80 \mathrm{~mL})$ were employed to afford $\mathbf{3 S}$ as a transparent liquid $(3.60 \mathrm{~g}, 78.0 \%) .{ }^{1} \mathrm{H}$ NMR $\left(400 \mathrm{MHz}, \mathrm{CDCl}_{3}\right): \delta 6.92-6.90(\mathrm{~m}, 4 \mathrm{H}), 4.07-4.02(\mathrm{~m}$, $4 \mathrm{H}), 1.91-1.85(\mathrm{~m}, 2 \mathrm{H}), 1.73-1.51(\mathrm{~m}, 5 \mathrm{H}), 1.38-1.06(\mathrm{~m}, 19 \mathrm{H}), 0.97-0.84(\mathrm{~m}, 22 \mathrm{H}) \mathrm{ppm} ;{ }^{13} \mathrm{C}$ NMR $(75$ $\left.\mathrm{MHz}, \mathrm{CDCl}_{3}\right): \delta 149.28,120.98,114.08,67.64,39.37,39.28,37.51,37.48,37.41,37.38,37.29,36.38$, $36.32,32.81,29.96,29.95,27.98,24.82,24.80,24.72,24.41,22.71,22.70,22.61,19.73,19.70,19.68$, 19.66 ppm; IR (ATR): $\mathrm{n}=2935,2924,2868,1593,1503,1463,1454,1380,1366,1330,1252,1221,1121$, 1047, 1038, 979, $736 \mathrm{~cm}^{-1}$; MS(MALDI-TOF): $\mathrm{m} / \mathrm{z}$ calcd: 460.78 [M] ; found: 460.57; elemental analysis: calcd (\%) for CH: C 80.81, H 12.25; found: C 79.70, H 12.54.

\section{$\underline{\text { 4-(3,7-Dimethyldodecyloxy)-5-(3S)-(3,7-dimethyloctcyloxy)-1,2-dinitrobenzene (2S) }}$}

Compound $2 S$ was prepared according to the procedure used to obtain $2 \boldsymbol{R}$. More specifically, $3 \boldsymbol{S}$ (1.84 g, $4.0 \mathrm{mmol}), \mathrm{CH}_{2} \mathrm{Cl}_{2}(40 \mathrm{~mL}), \mathrm{CH}_{3} \mathrm{COOH}(20 \mathrm{~mL}), \mathrm{HNO}_{3}(5.0 \mathrm{~mL})$, and fuming $\mathrm{HNO}_{3}(10 \mathrm{~mL})$ were employed to obtain $2 S$ as a yellow solid (1.85 g, 84.1\%) ${ }^{1} \mathrm{H}$ NMR (400 MHz, $\left.\mathrm{CDCl}_{3}\right): \delta 7.31(\mathrm{~m}, 2 \mathrm{H}), 4.16-$ $4.12(\mathrm{~m}, 4 \mathrm{H}), 1.94-1.89(\mathrm{~m}, 2 \mathrm{H}), 1.69-1.50(\mathrm{~m}, 7 \mathrm{H}), 1.38-1.07$ (m, 21H), 0.98 (m, 6H), 0.90-0.84 (m, 16H) ppm; ${ }^{13} \mathrm{C}$ NMR $\left(75 \mathrm{MHz}, \mathrm{CDCl}_{3}\right): \delta 151.78,136.50,107.83,68.66,39.36,39.18,37.37,37.30$, $37.28,37.18,37.15,37.16,35.67,35.61,32.80,29.91,29.89,27.97,24.80,24.67,24.38,22.69,22.68$, 22.60, 22.58, 19.71, 19.64, 19.61, 19.59 ppm; IR (ATR): $\mathrm{n}=2930,2924,2869,1587,1527,1466,1373$, 1335, 1290, 1220, 1036, 958, 874, 869, 811, 751, 719, 665, $619 \mathrm{~cm}^{-1}$; MS(MALDI-TOF): m/z calcd: 550.77 $[\mathrm{M}]^{+}$; found: 573.57; elemental analysis: calcd (\%) for CHN: C 67.60, H 9.88, N 5.09; found: C 66.95, H 9.91, N 5.36. 


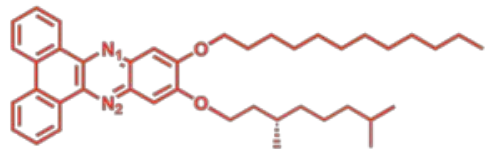

$1 S^{\prime}$

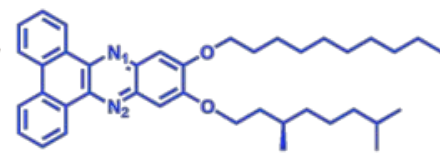

$1 R^{\prime}$

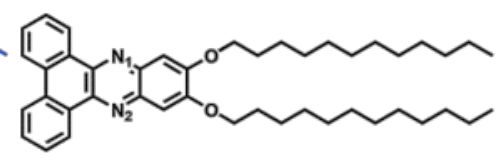

$1 L$

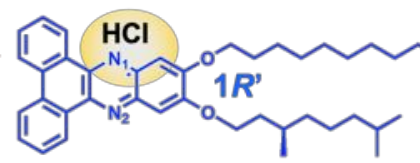

$\mathrm{N} 1\left(1 R^{\prime}-\mathrm{HCl}\right)$

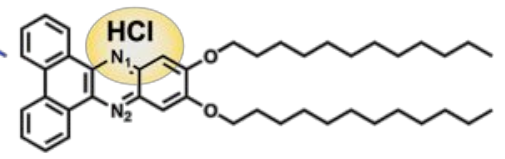

$\mathrm{N} 1(1 L-\mathrm{HCl})$

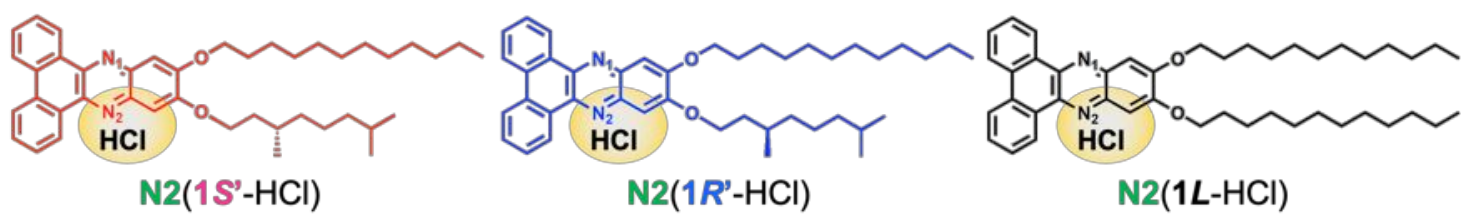

Scheme S2. Molecular structures of $1 S^{\prime}, \mathbf{1} R^{\prime}$, and $\mathbf{1} L$ and their corresponding $\mathrm{HCl}$ derivatives. 


\section{S2. Experimental Data}

(a)

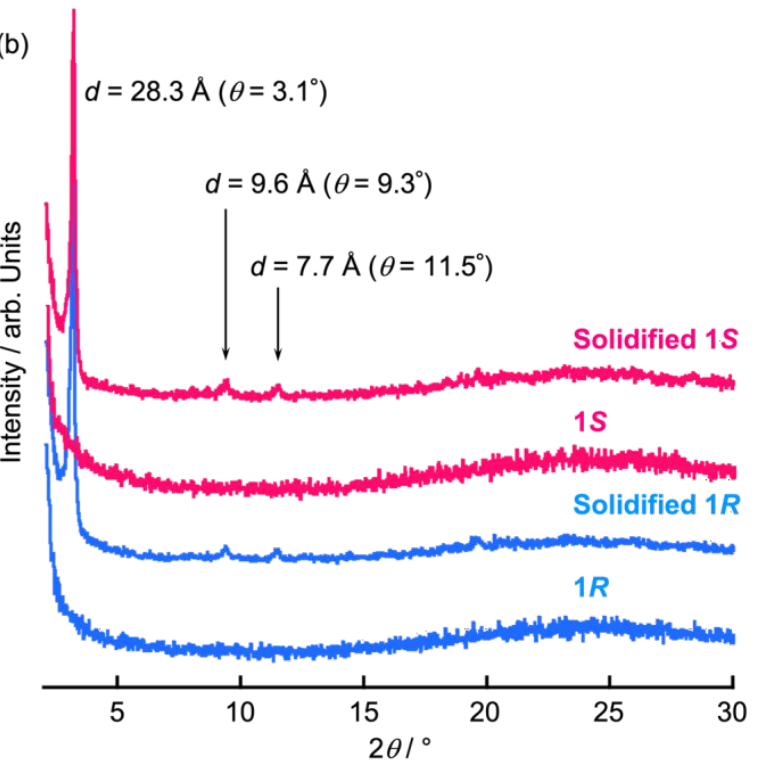

(c)

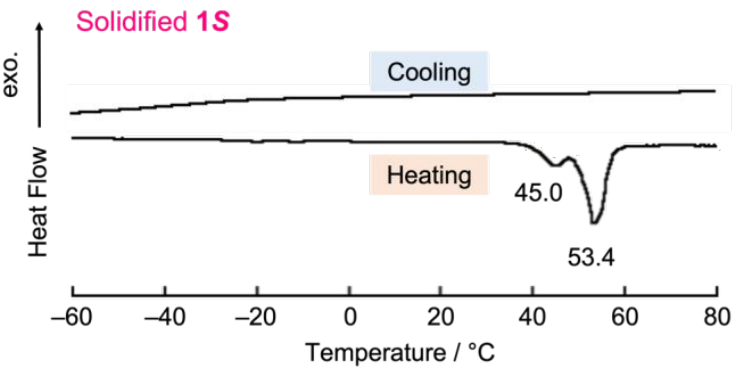

Solidified $1 R$

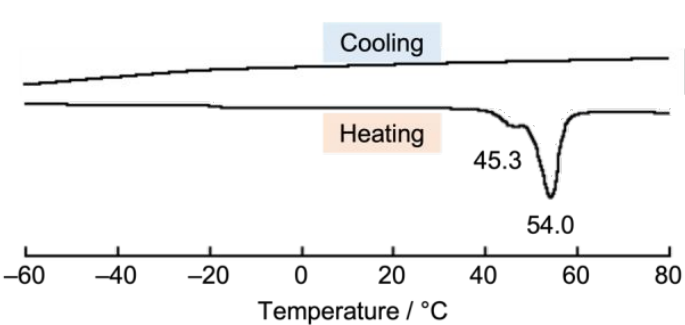

DSC Sequence : $25^{\circ} \mathrm{C} \longrightarrow-100^{\circ} \mathrm{C} \stackrel{\text { Heating }}{\longrightarrow} 100^{\circ} \mathrm{C} \stackrel{\text { Cooling }}{\longrightarrow}-100^{\circ} \mathrm{C}$

Figure S1. (a) POM observations (top: after heating; bottom: after solidification) of $1 S$ and $1 R$ at room temperature. Arrows indicate the analyzer and polarizer (P) axes. (b) XRD patterns of $\mathbf{1 S}$ and $\mathbf{1} \boldsymbol{R}$ at room temperature. (c) DSC traces of solidified $\mathbf{1 S}$ and $\mathbf{1 R}$ at a scanning velocity of $10 \mathrm{~K} / \mathrm{min}$. The DSC temperature sequence is also indicated.

It should be noted that we observed the solidification of $1 S$ and $1 R$ after allowing to stand for $1 \mathrm{~d}$, and the behaviors of these solid products were evaluated by XRD, DSC measurements, and POM observations, as outlined in Figure S1. After the solidification of $1 S$ and $1 R$, the XRD patterns of both compounds exhibited three peaks in the small-angle region, indicating the transformation into lamellar-like aggregated structures. The POM observations showed birefringence due to the formation of aggregated structures. DSC measurements revealed that $1 S$ and $1 R$ possessed melting points of 53.4 and $54.0{ }^{\circ} \mathrm{C}$, respectively. On the other hand, no peak corresponding to transformation into the solid state was observed, although $T_{\mathrm{g}}$ values of $-23.8{ }^{\circ} \mathrm{C}$ for $\mathbf{S S}$ and $-22.9^{\circ} \mathrm{C}$ for $\mathbf{1 R}$ were observed on cooling. In addition, no peak attributed to the 
phase transition to a solid state was observed upon subsequent heating. These results indicate that $1 S$ and $\boldsymbol{1 R}$ should adopt a liquid state at room temperature over the range of the experimental timescale.
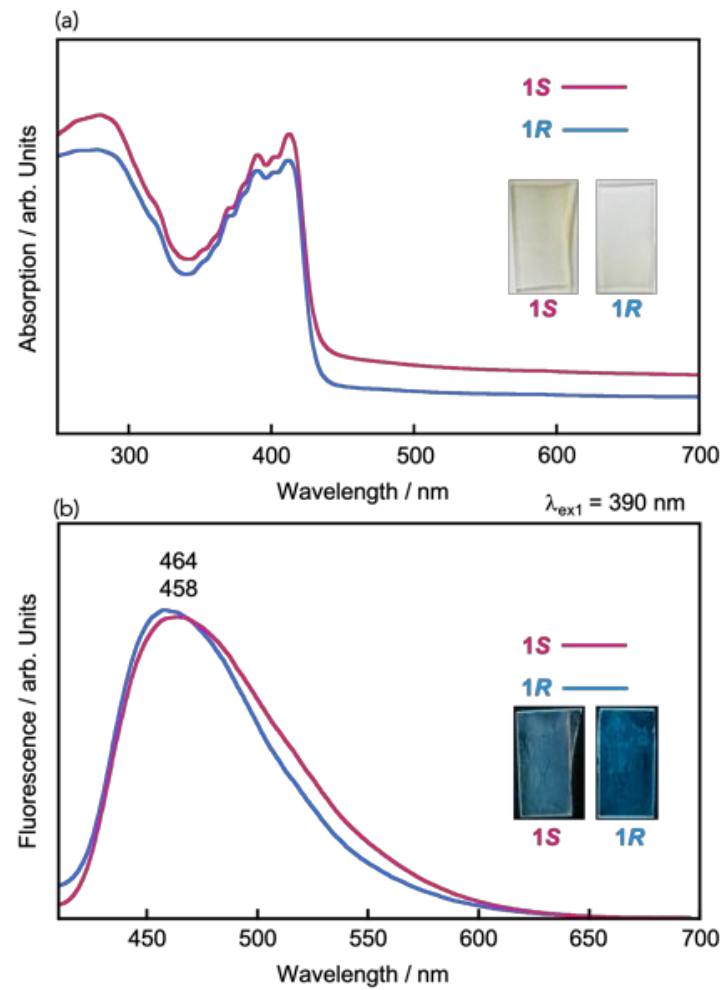

Figure S2. (a) UV-vis absorption and (b) FL spectra of $\mathbf{1 S}-\mathbf{H C l}$ and $\mathbf{1} \boldsymbol{R}-\mathbf{H C l}$ exposed to air for 1 day at room temperature.

$1 S-\mathrm{HCl}$ and $1 R-\mathrm{HCl}$ were found to be recovered into their $1 S$ and $1 R$ initial states by exposure to air for 1 day at room temperature or upon heating, thereby suggesting that the stimuli response is reversible. 

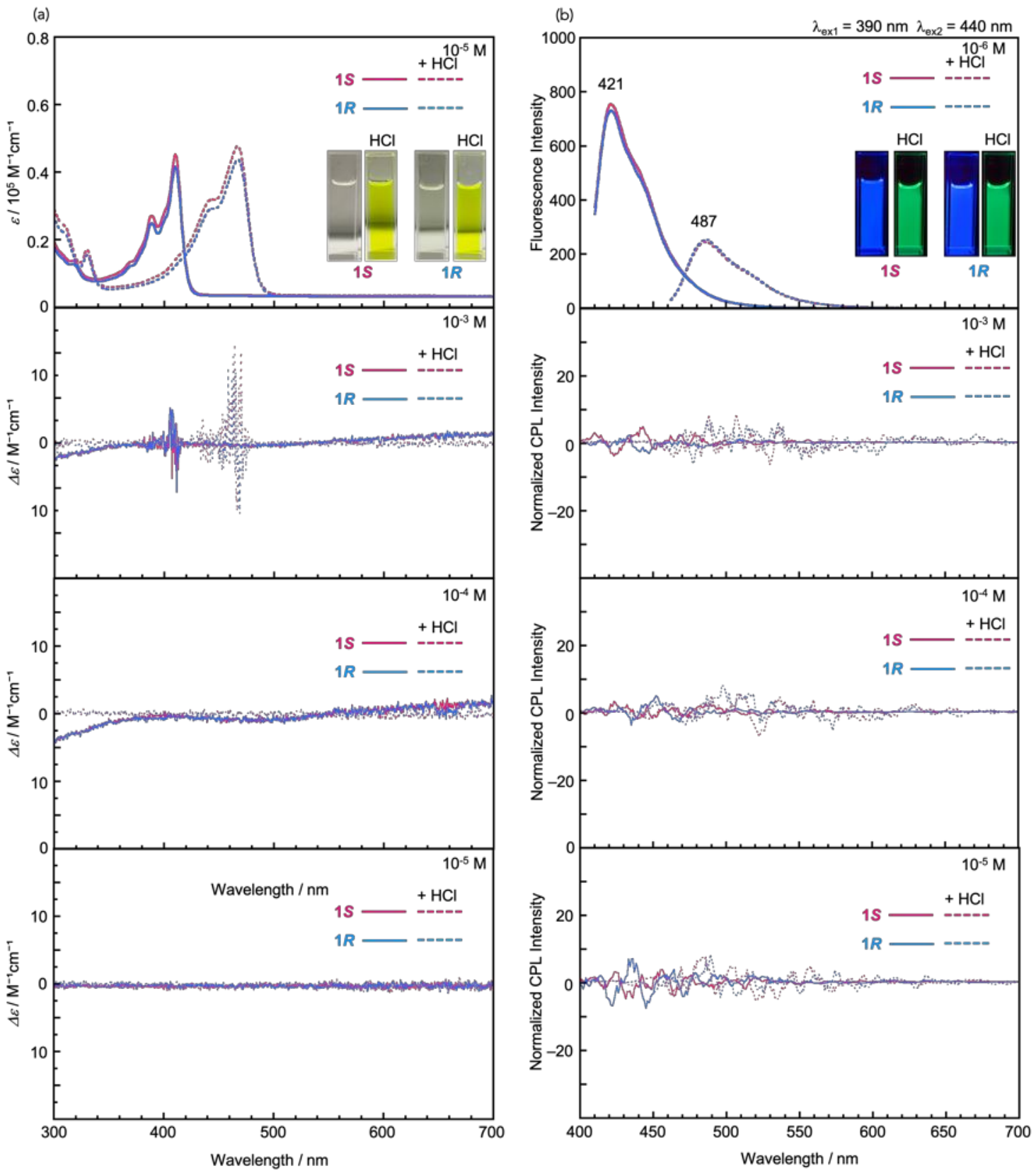

Figure S3. (a) UV-vis absorption spectra (top) and concentration-dependent CD spectra of $1 S, 1 R, 1 S$-HCl, and $\mathbf{1 R}$-HCl. Photographic images were obtained in solutions of $\mathrm{CHCl}_{3}\left(10^{-5} \mathrm{M}\right)$ under ambient light. (b) FL spectra (top) and concentration-dependent CPL spectra of $1 S, 1 R, 1 S$-HCl, and $1 R-H C l$. Photographic images were obtained under $365 \mathrm{~nm}$ light. 


\section{S3. Dipole moments and stacking structures of the $N$-heteroacene frameworks}

The time-dependent density functional theory (TD-DFT) calculation for a model compound of $\mathbf{1 S}-\mathbf{H C l}$ and $\mathbf{1} \boldsymbol{R}-\mathbf{H C l}$ was conducted at the B3LYP/6-31g(d) level of theory to estimate their permanent dipole moment and transition electric dipole moment for HOMO-LUMO transition. The result shows the permanent dipole (3.74 D) directs from $\mathrm{N}$ bonding with $\mathrm{HCl}$ to the other $\mathrm{N}$ (the solid allow in Figure $\mathrm{S} 4$ ), and the electric transition dipole directs along the long axis of the frameworks (the dashed allow in Figure S4).

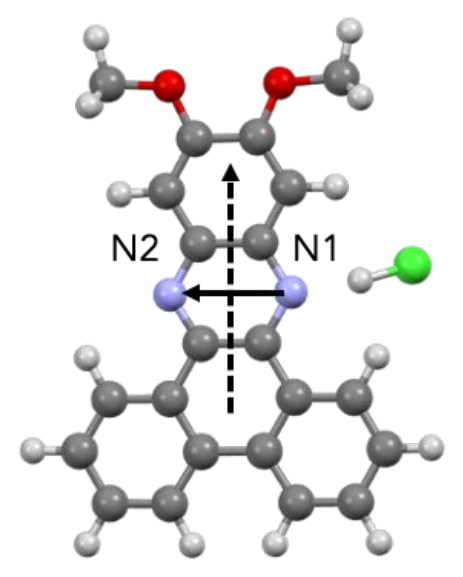

Figure S4. Dipole moments of the N-heteroacene framework with $\mathrm{HCl}$. The solid arrow indicates the permanent dipole moment and the dashed arrow shows the transition electronic dipole moment for HOMOLUMO transition. The two alkyl moieties of the model compound are substituted with methyl groups instead of the branched long alkyl moieties to simplify the calculation.

To examine the stacking structure of dimer in terms of the permanent dipole moment that attracts two $\mathrm{N}$ heteroacene frameworks, we focus on the probability distribution of the torsion angle $\tau$ for two permanent dipole moments of the dimer in Fig. S5a (see the solid arrow of Figure S4). The probability distributions of the torsion angle $\tau$ for the $\mathbf{S}$ - $\mathbf{H C l}$ and $\mathbf{1 R}$ - HCl systems have a peak at $\tau= \pm \pi$, indicating that the permanent dipole moments of the stacking molecule are stable in anti-parallel direction, whereas such structure is not seen in the systems without $\mathrm{HCl}$ because of lacking of the dipole-dipole attractive interaction. Combining with the results shown in Fig. 3 in the main text, there are two kinds of stacking structure for the $\mathbf{1 S}$-HCl and $\mathbf{1 R}-\mathbf{H C l}$ systems; one is a stacking framework in parallel direction [left side of Fig. S5b], and the other is that in anti-parallel direction [right side of Fig. S5b]. These two structures are essential for explaining the measured CD spectra, as discussed below. 


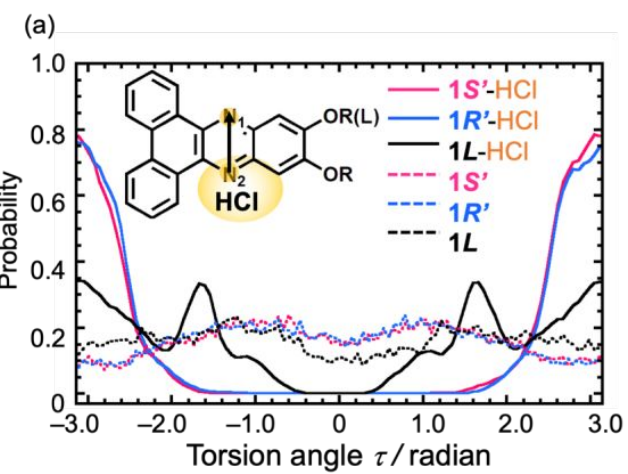

(b)
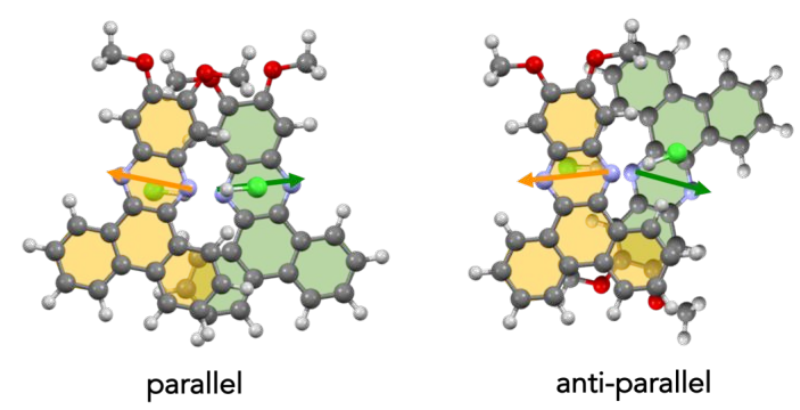

Figure S5. (a) Probability distributions of the stacking structures of the $N$-heteroacene frameworks as a function of the torsion angle $\tau$ between two N-N vectors for the dimer (panel b), where the N-N vector with $\mathrm{HCl}$ is defined as the vector directing from $\mathrm{N}$ bonding to $\mathrm{HCl}$ to the other $\mathrm{N}$ to mimic the permanent dipole vector. $\mathrm{HCl}$ molecules are omitted for clarity in panel $\mathrm{b}$. The sampling in panel a was taken for dimer whose distance of two $\mathrm{N}$ is within $4.72 \AA$ (the first minimum position of the radial distribution function for $\mathrm{N}-\mathrm{N}$ ).

\section{S4. Calculation of CD spectrum}

A typical snapshot of a tetramer structure that can be seen in the present MD simulation for 1S'-HCl system is shown in Fig. S6, indicating that the central pair of the heteroacene frameworks (numbered 2 and 3 in Fig. S6) in 1S'-HCl system actually forms the left-handed chiral structure. Conversely, the righthanded chiral structure was formed in 1R'-HCI system (not shown). As is seen in the snapshot shown in Fig S6, both side of the central pair (i.e., 1 and 4) typically forms the anti-parallel stacking structure (upsidedown pair). To examine the consistency between the chiral structure predicted by MD simulation and the sign of the experimentally observed CD spectra, the CD spectra were calculated by quantum chemical calculation, where the transition dipole moment and the spectra were calculated by B3LYP functional based on the TD-DFT using 6-31G(d) basis set by Gaussian 09. ${ }^{3}$ The lineshape of the CD spectrum was generated with the help of Multiwfn 3.8. ${ }^{4}$

The lowest-energy dipole-allowed transition is typically observed in CD spectra between the highest occupied molecular orbital (HOMO) and the lowest unoccupied molecular orbital (LUMO). The present TD-DFT calculation showed the transition dipole directs along the long axis of the molecule (see Fig. S4). We first calculated CD spectra of left-handed and right-handed dimer shown in Fig. S5b. As is predicted from the exciton chirality method, the calculated CD spectra seen in the left panels of Fig. S7 showed that the left-handed (right-handed) backbone has the negative (positive) band in the longer wavelength region [i.e., the negative (positive) sign of the first Cotton effect is expected for the left- (right-) handed backbone]. Next, we examined the case of the tetramer structure that has the same dimer structure as the left panel of Figure S7 for the central pair (2 and 3) and has the upside-down pair for both sides (1 and 4). Contrary to the case of the simple left-handed and right-handed dimer mentioned above, the CD spectrum of the tetramer for the left-handed (right-handed) frameworks shows a positive (negative) band in the longer 
wavelength region. Thus, the chiral structure predicted by the present MD simulation is consistent to the optical activity measured by the experimental CD spectra shown in Fig. 2 in the main text.
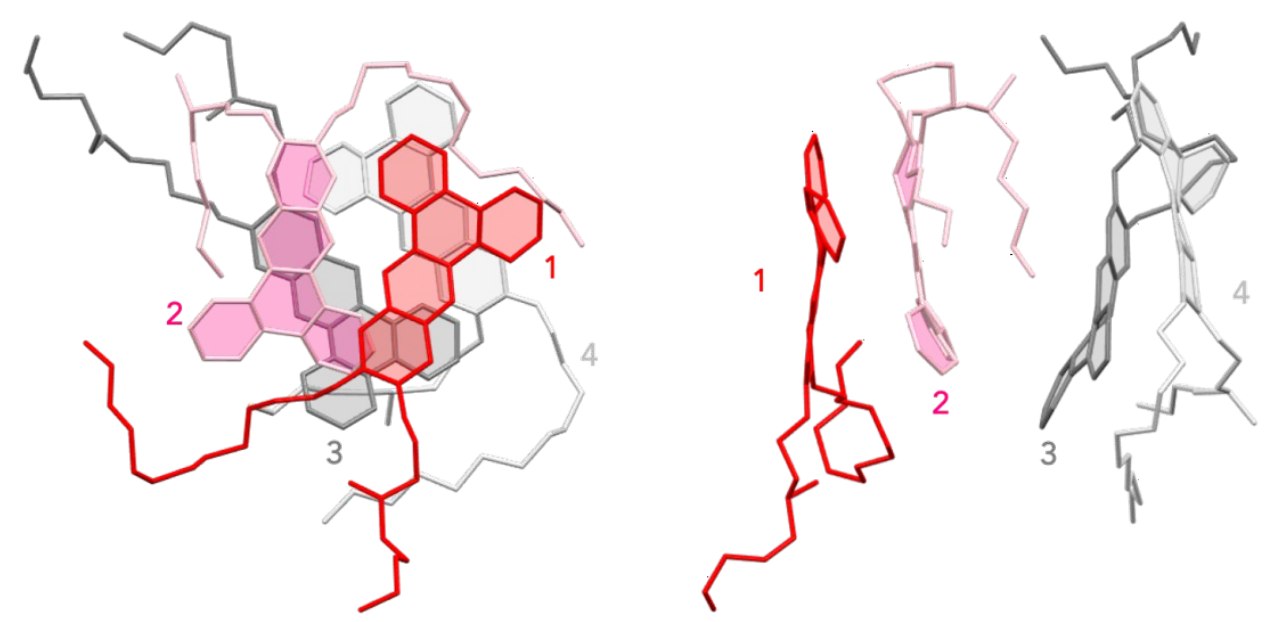

Figure S6. A typical tetramer structure taken in the present MD simulation of 1S'-HCl system.
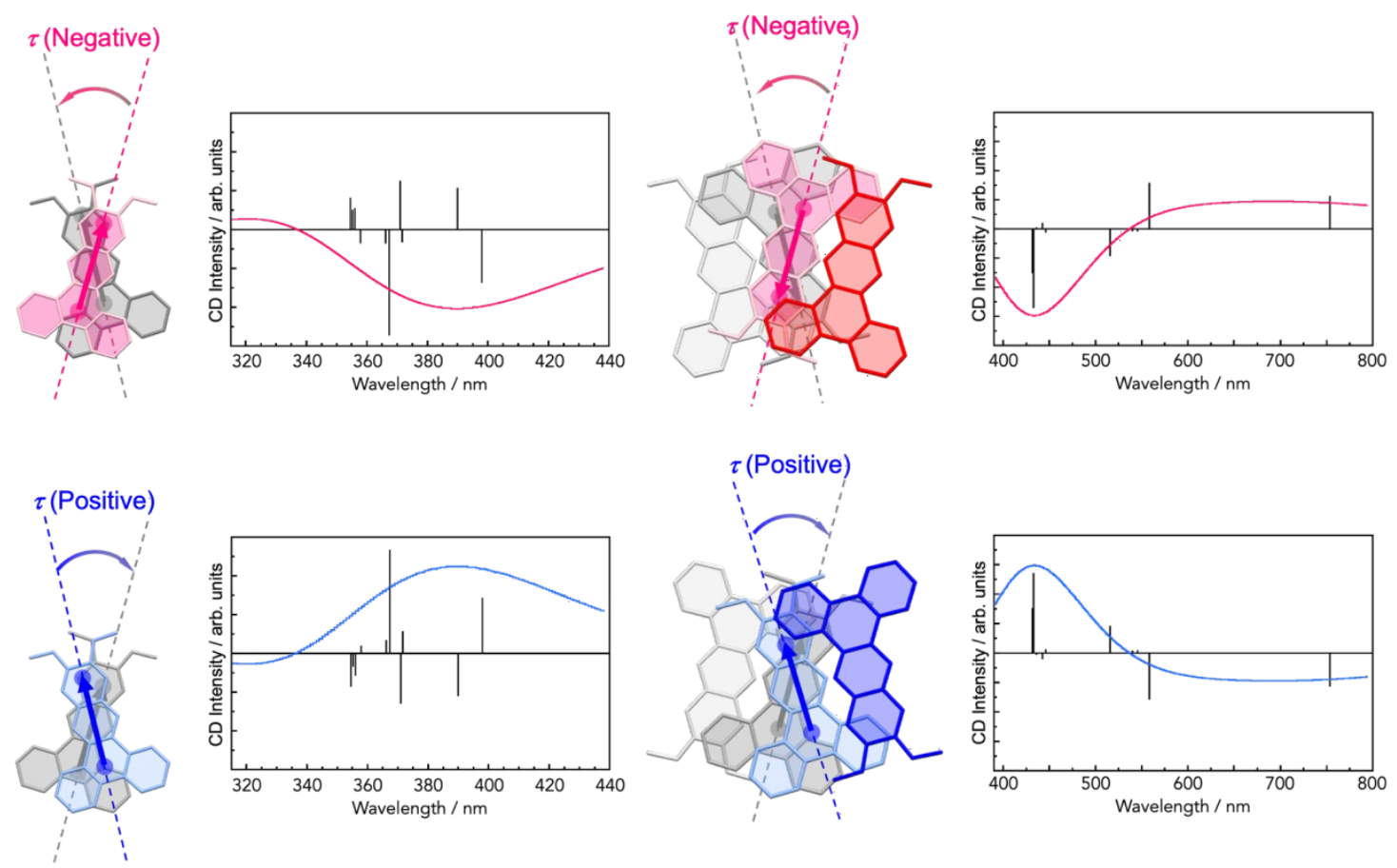

Figure S7. CD spectra estimated by the present TD-DFT calculation. Left panels: a dimer structure with left-handed (upper) and right-handed (lower) structure. Right panels: a tetramer structure that has the same dimer structure as the left panel for the central pair (2 and 3 numbered in Fig. S6) and has the anti-parallel stacking structure for both side (1 and 4 numbered in Fig. S6). 

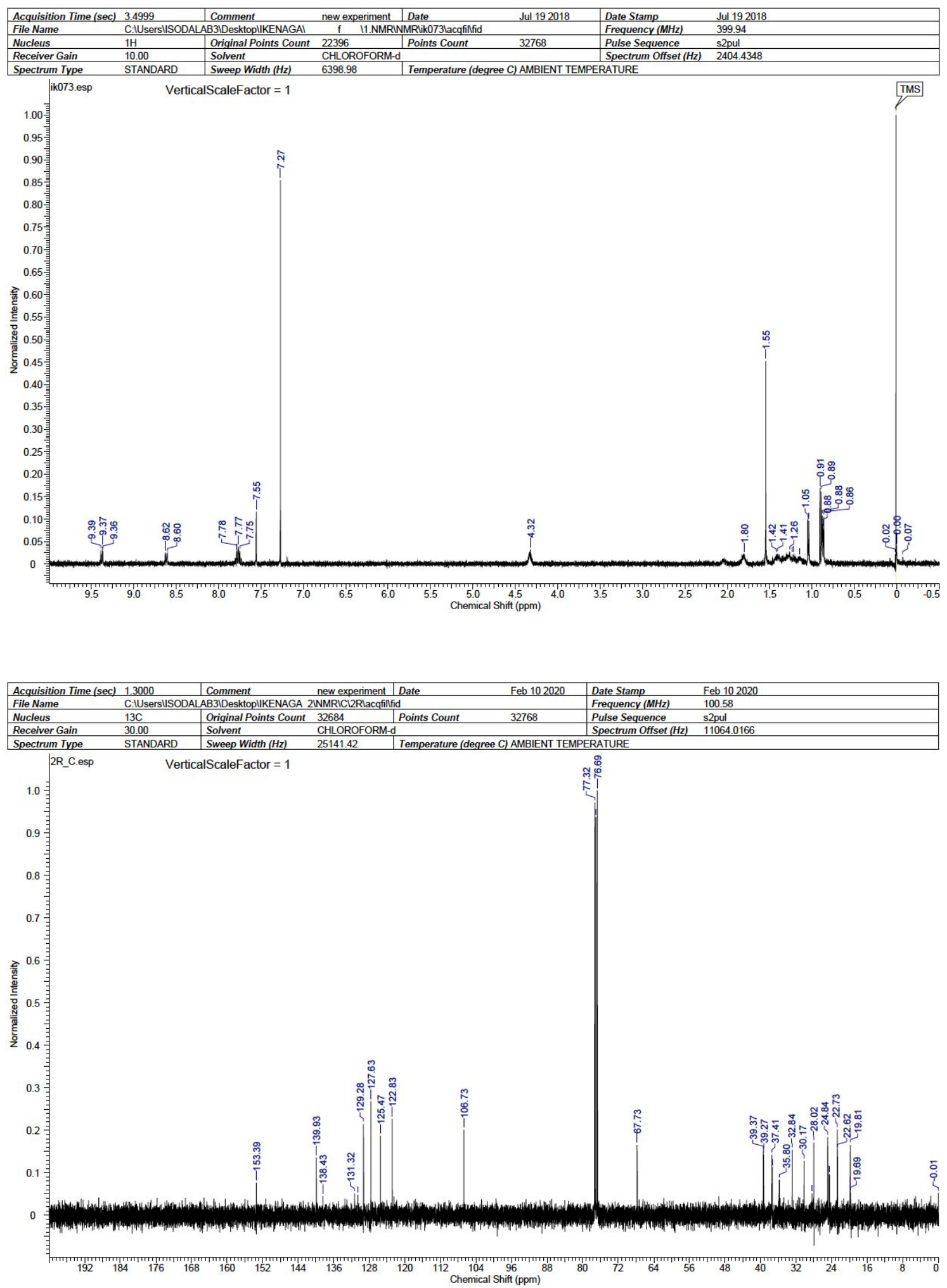

Figure S8. ${ }^{1} \mathrm{H}$ (top) and ${ }^{13} \mathrm{C}$ NMR (bottom) spectra of $\mathbf{1 R}$. 

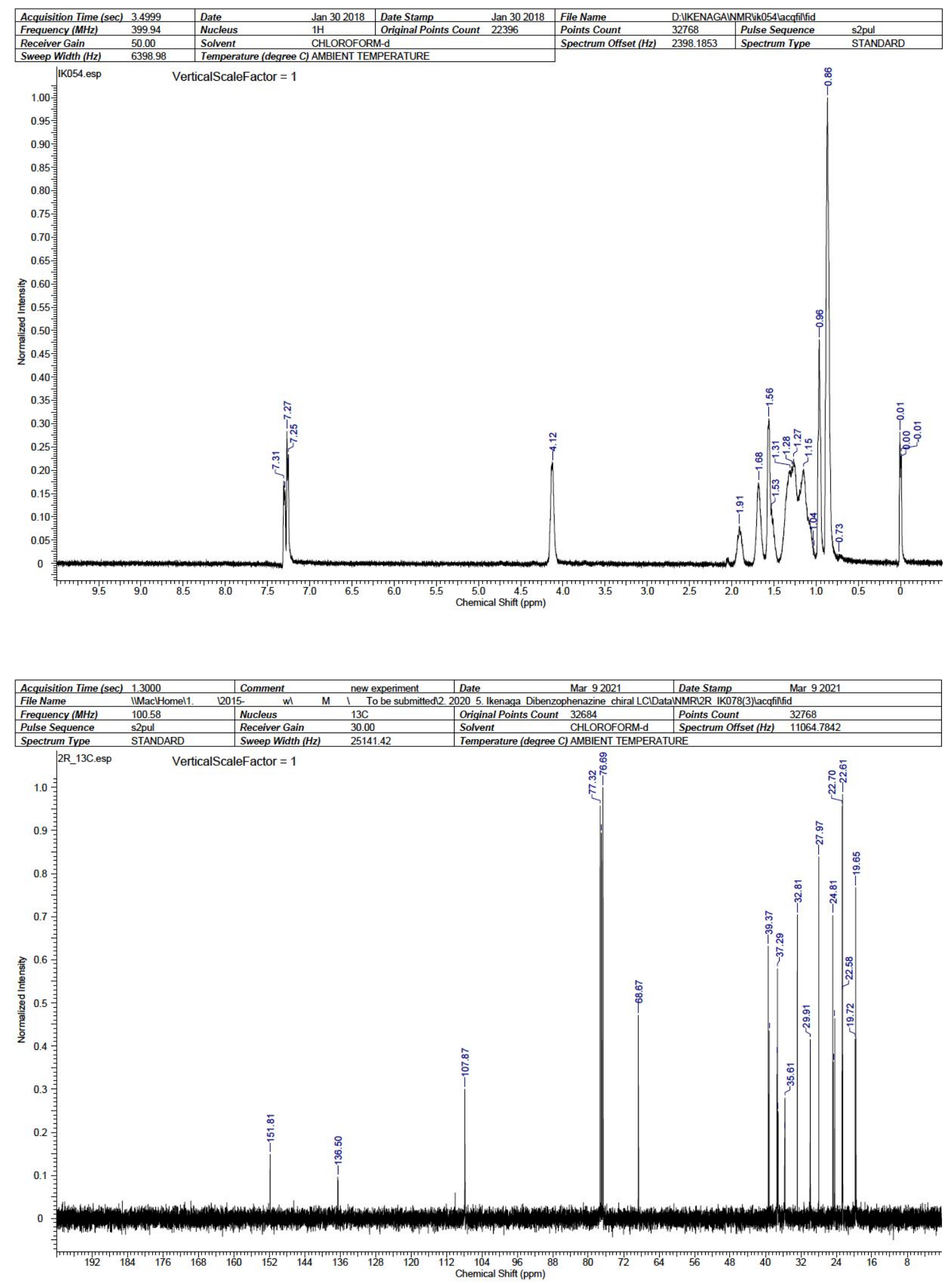

Figure S9. ${ }^{1} \mathrm{H}$ (top) and ${ }^{13} \mathrm{C}$ NMR (bottom) spectra of $\mathbf{2}$. 

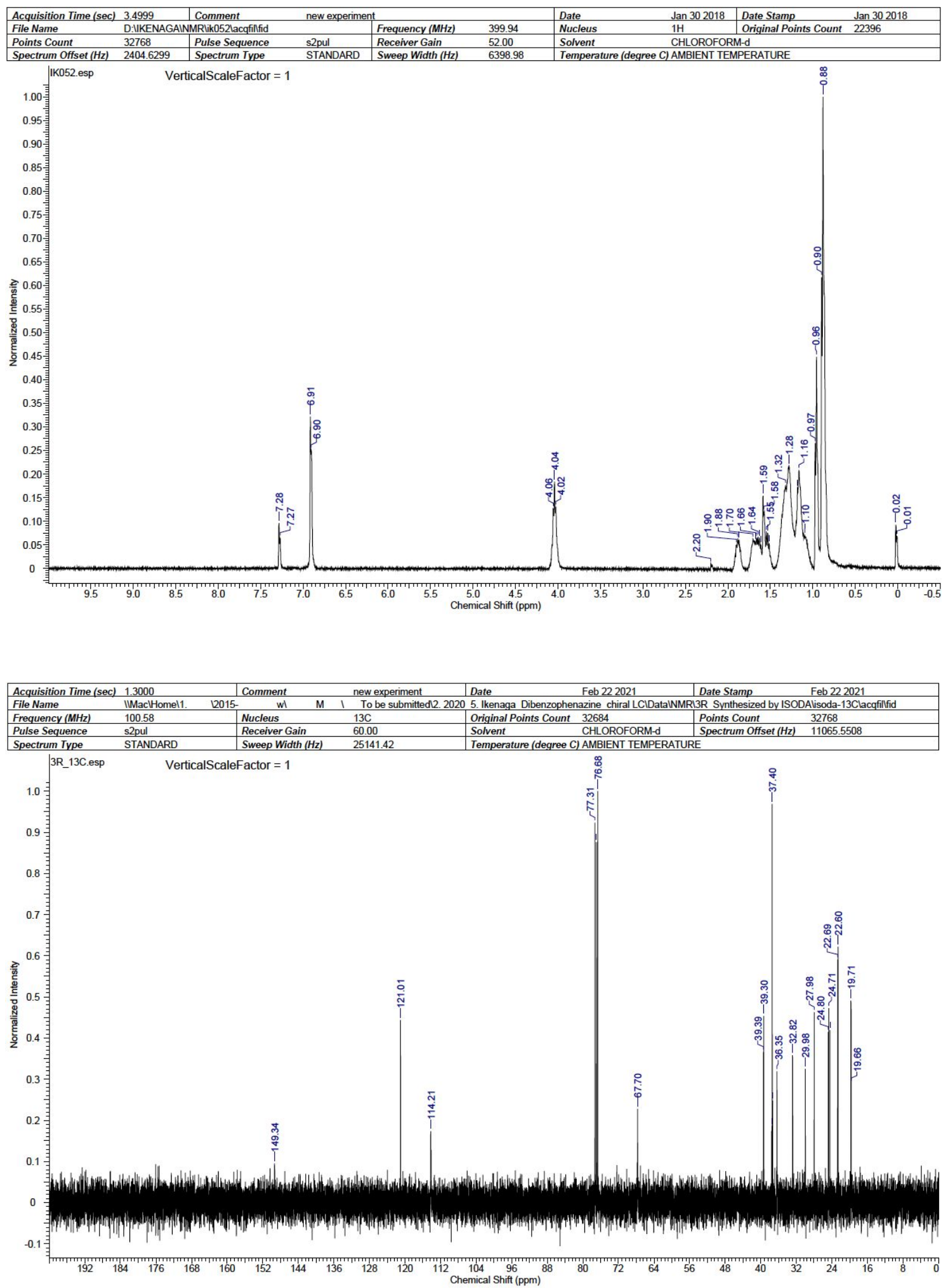

Figure S10. ${ }^{1} \mathrm{H}$ (top) and ${ }^{13} \mathrm{C}$ NMR (bottom) spectra of $\mathbf{3 R}$. 

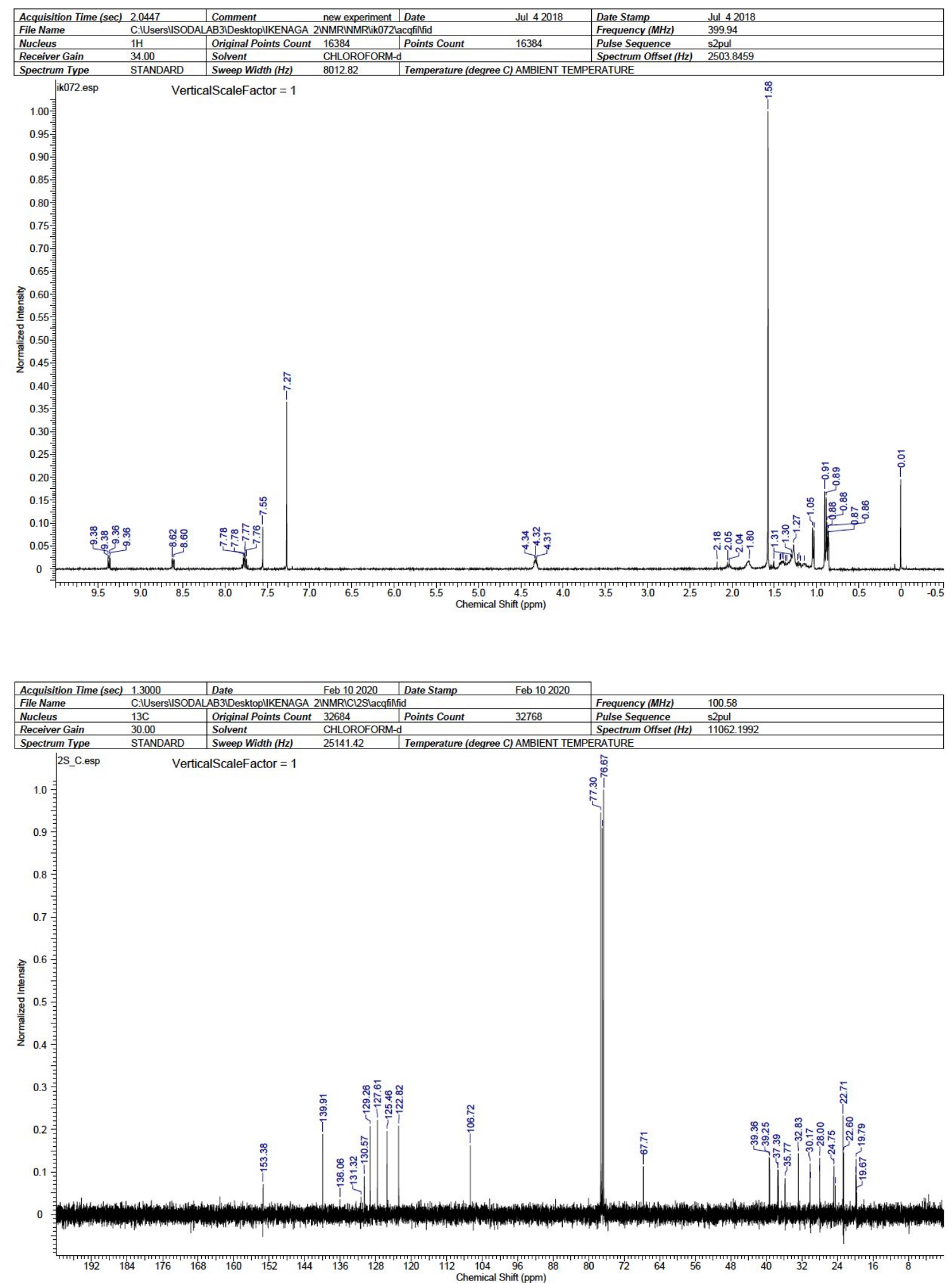

Figure S11. ${ }^{1} \mathrm{H}$ (top) and ${ }^{13} \mathrm{C}$ NMR (bottom) spectra of $\mathbf{1 S}$. 

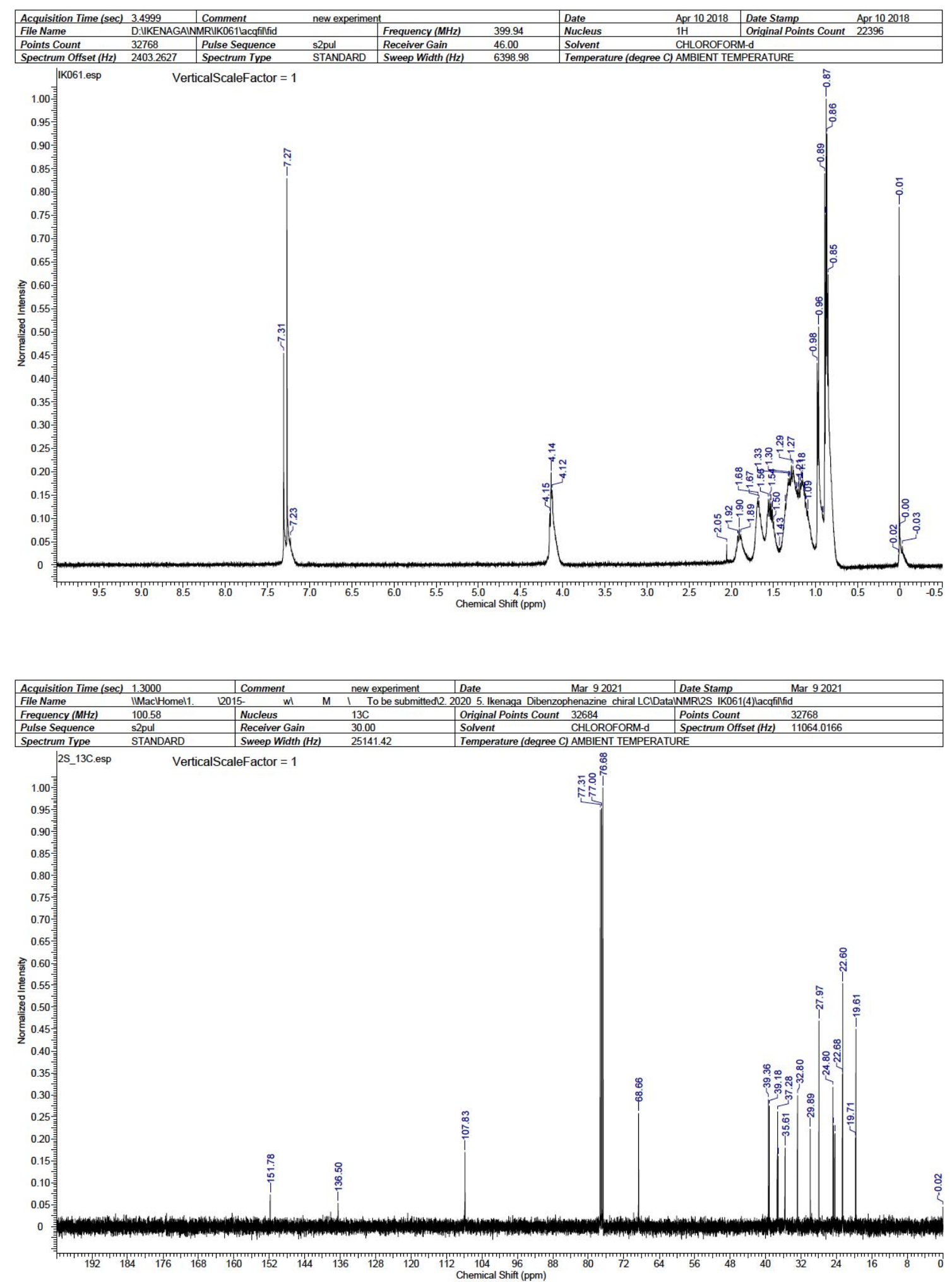

Figure S12. ${ }^{1} \mathrm{H}$ (top) and ${ }^{13} \mathrm{C}$ NMR (bottom) spectra of $\mathbf{2 S}$. 

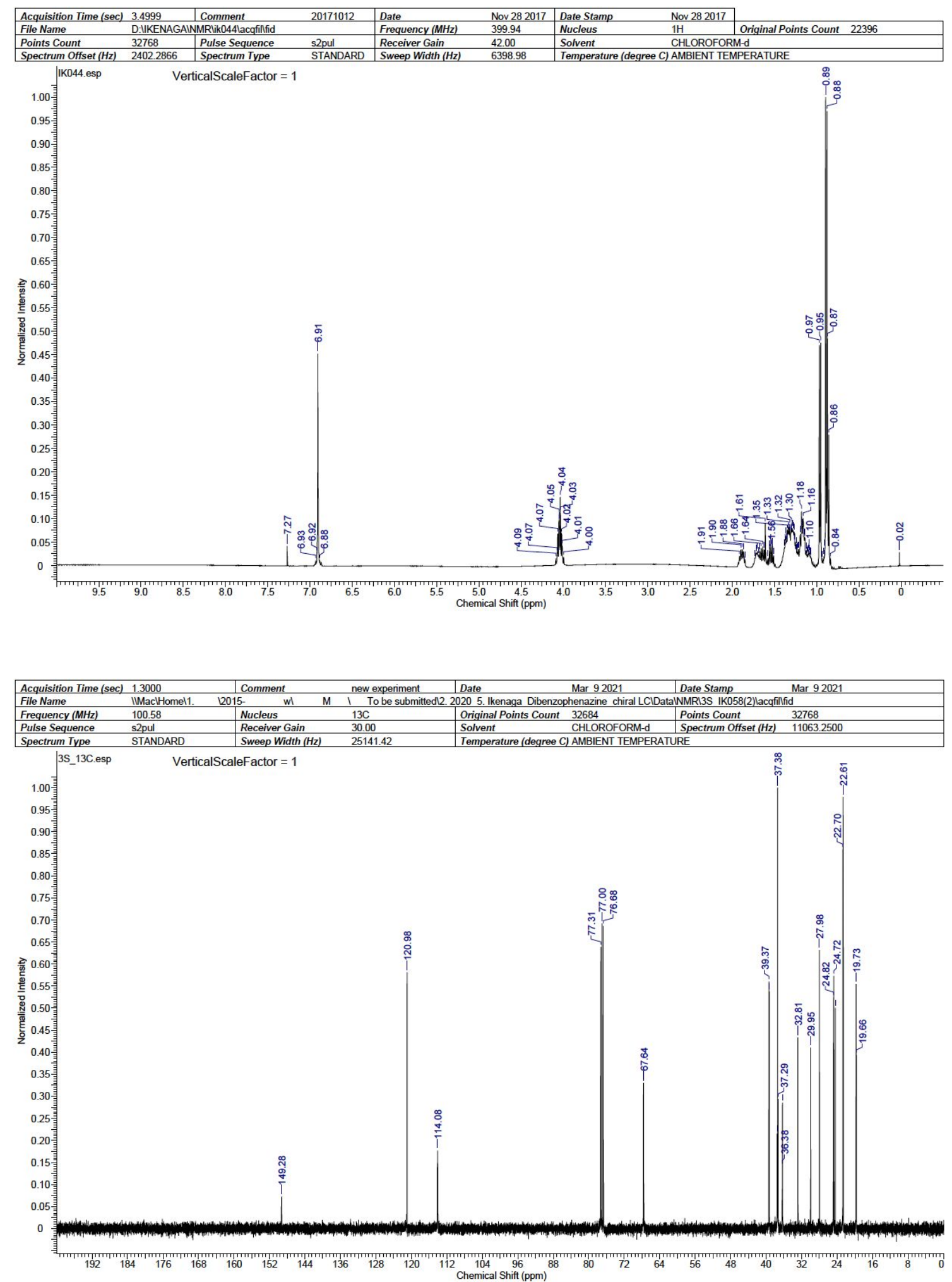

Figure S13. ${ }^{1} \mathrm{H}$ (top) and ${ }^{13} \mathrm{C}$ NMR (bottom) spectra of $\mathbf{3 S}$. 

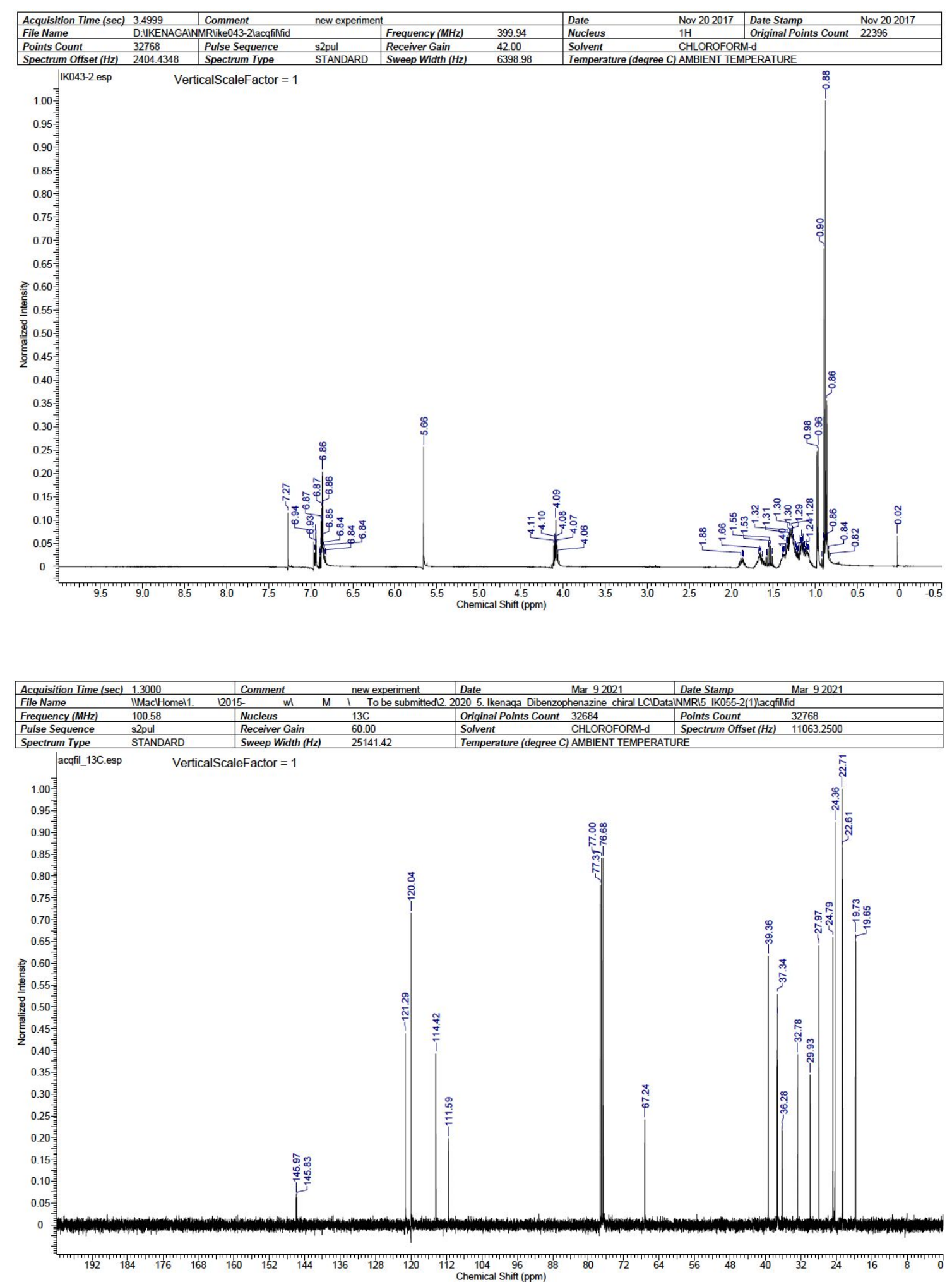

Figure S14. ${ }^{1} \mathrm{H}$ (top) and ${ }^{13} \mathrm{C}$ NMR (bottom) spectra of 5. 


\section{References}

(1) Isoda, K.; Ishiyama, T; Mutoh, Y.; Matsukuma, D. Stimuli-responsive room-temperature N-heteroacene liquid: In situ observation of the self-assembling process and its multiple properties, ACS Appl. Mater. \& Interfaces 2019, 11, 12053-12062.

(2) Wang, J.; Wolf, R. M.; Caldwell, J. W.; Kollman, P. A.; Case, D. A. Development and testing of a general amber force field, J. Comput. Chem. 2004, 25, 1157-1174.

(3) Frisch, M. J.; Trucks, G. W.; Schlegel, H. B.; Scuseria, G. E.; Robb, M. A.; Cheeseman, J. R.; Scalmani, G.; Barone, V.; Petersson, G. A.; Nakatsuji, H.; Li, X.; Caricato, M.; Marenich, A.; Bloino, J.; Janesko, B. G.; Gomperts, R.; Mennucci, B.; Hratchian, H. P.; Ortiz, J. V.; Izmaylov, A. F.; Sonnenberg, J. L.; Williams-Young, D.; Ding, F.; Lipparini, F.; Egidi, F.; Goings, J.; Peng, B.; Petrone, A.; Henderson, T.; Ranasinghe, D.; Zakrzewski, V. G.; Gao, J.; Rega, N.; Zheng, G.; Liang, W.; Hada, M.; Ehara, M.; Toyota, K.; Fukuda, R.; Hasegawa, J.; Ishida, M.; Nakajima, T.; Honda, Y.; Kitao, O.; Nakai, H.; Vreven, T.; Throssell, K.; Montgomery, J. A.; Jr., J. E. P.; Ogliaro, F.; Bearpark, M.; Heyd, J. J.; Brothers, E.; Kudin, K. N.; Staroverov, V. N.; Keith, T.; Kobayashi, R.; Normand, J.; Raghavachari, K.; Rendell, A.; Burant, J. C.; Iyengar, S. S.; Tomasi, J.; Cossi, M.; Millam, J. M.; Klene, M.; Adamo, C.; Cammi, R.; Ochterski, J. W.; Martin, R. L.; Morokuma, K.; Farkas, O.; Foresman, J. B.; Fox, D. J. Gaussian 09, A.02; Gaussian, Inc.: Wallingford CT, 2009.

(4) Lu, T.; Chen, F. Multiwfn: A multifunctional wavefunction analyzer, J. Comput. Chem. 2012, 34, 580592. 